\title{
EVALUASI KEKUMUHAN PADA KAWASAN PERUMAHAN PASAR LAMBARO KECAMATAN INGIN JAYA KABUPATEN ACEH BESAR
}

\author{
H. Adlan ${ }^{1)}$, A. Yulianur ${ }^{2)}$, Izziah $^{3)}$ \\ Magister Teknik Sipil, Universitas Syiah Kuala, Banda Aceh \\ Email: haidiadlan@gmail.com ${ }^{1)}$, fia_7anur@unsyiah.ac.id ${ }^{2)}$, \\ izziah.hasan@unsyiah.ac.id ${ }^{3)}$
}

DOI: http://dx.doi.org/10.29103/tj.v11i1.434

(Received: December 2020 / Revised: January 2021 / Accepted: January 2021)

\begin{abstract}
Abstrak
Kawasan Pasar Lambaro merupakan satu-satunya kawasan kumuh yang terdapat di Kecamatan Ingin Jaya dengan luas kumuh mencapai 32,14 Ha. Dalam luasan tersebut, sebelah utara Kawasan Pasar Lambaro terdapat salah satu kawasan perumahan yang telah banyak mengalami penurunan kualitas infrastruktur dengan luas perumahan kumuh mencapai 3,9 Ha. Kawasan perumahan tersebut mempunyai ketidakteraturan bangunan, tingkat kepadatan bangunan yang tinggi, kualitas bangunan yang rendah, serta sarana dan prasarana yang tidak memenuhi persyaratan teknis. Penelitian ini bertujuan untuk mengevaluasi tingkat kekumuhan pada kawasan perumahan Pasar Lambaro, mengidentifikasi skala prioritas penanganan kawasan perumahan kumuh di Pasar Lambaro, dan menemukan solusi penanganan kawasan perumahan kumuh di Pasar Lambaro. Penelitian ini menggunakan metode kuantitatif melalui observasi dan wawancara. Teknik analisis data menggunakan analisis skoring (pembobotan) dan analisis deskriptif. Hasil penelitian menunjukkan bahwa tingkat kekumuhan pada kawasan perumahan Pasar Lambaro adalah termasuk dalam klasifikasi kumuh ringan dengan total nilai skor sebesar 25. Skala prioritas penanganan kawasan perumahan kumuh di Pasar Lambaro masuk dalam skala prioritas penanganan ke 3. Solusi penanganan kawasan perumahan kumuh di Pasar Lambaro dilakukan melalui pemugaran untuk lahan legal dan pemukiman kembali untuk lahan ilegal yang difokuskan pada aspek bangunan gedung, penyediaan air minum, pengelolaan air limbah, pengelolaan persampahan, dan proteksi kebakaran.
\end{abstract}

Kata kunci: kekumuhan, perumahan, permukiman, penanganan, infrastruktur

\begin{abstract}
The Lambaro Market area is the only slum area located in the District of Ingin Jaya with a slum area of 32.14 hectares. Within this area, to the north of the Lambaro Market Area, there is a housing area that has experienced a lot of deterioration in the quality of its infrastructure, with a slum housing area of up to 3.9 hectares. The residential area has building irregularities, high building density, low quality of buildings, and infrastructures that do not meet technical requirements. This study aims to evaluate the level of slum in the Pasar Lambaro housing area, identify the priority scale of handling slum housing areas in the Lambaro Market, and find solutions for handling slum housing areas in the Lambaro Market. This research uses quantitative methods through observation and interviews. The data analysis technique used a
\end{abstract}


scoring analysis (weighting) and descriptive analysis. The results show that the level of slum in the Pasar Lambaro housing area is classified as a mild slum with a total score of 25. The priority scale for handling slum housing areas in Lambaro Market is included in the 3rd priority scale of handling. Through restoration for legal land and resettlement for illegal land which focuses on aspects of building, drinking water supply, waste water management, solid waste management, and fire protection.

Keywords: slums, housing, settlements, handling, infrastructure

\section{Latar Belakang}

Permukiman kumuh merupakan permukiman yang tidak layak huni karena ketidakteraturan bangunan, tingkat kepadatan bangunan yang tinggi, kualitas bangunan yang rendah, serta sarana dan prasarana yang tidak memenuhi syarat. Kabupaten Aceh Besar merupakan salah satu kabupaten yang memiliki permukiman kumuh di Provinsi Aceh, yang meliputi 8 kawasan dari 6 kecamatan (Keputusan Bupati Aceh Besar Nomor 358 Tahun 2019 Tentang Penetapan Kawasan Permukiman Kumuh Perkotaan Dalam Wilayah Kabupaten Aceh Besar, 2019). Adapun kawasan yang dimaksud adalah Lhok Seunong di Kecamatan Seulimuem, Pasar Lambaro di Kecamatan Ingin Jaya, Lampeunurut Ujung Blang dan Garut di Kecamatan Darul Imarah, Baet dan Cadek di Kecamatan Baitussalam, Lambroe Bilue di Kecamatan Kuta Baro, dan Barona di Kecamatan Krueng Barona Jaya. Kawasan permukiman kumuh di Kabupaten Aceh Besar pada tahun 2016 mempunyai luas 190,5 ha. Pada tahun 2019 telah tertangani 60,48 ha di Kawasan Barona, sehingga luas kawasan permukiman kumuh menjadi 130,02 ha. Hal tersebut diketahui melalui Keputusan Bupati Aceh Besar Nomor 358 Tahun 2019 Tentang Penetapan Kawasan Permukiman Kumuh Perkotaan Dalam Wilayah Kabupaten Aceh Besar.

Pemerintah Kabupaten Aceh Besar dalam menetapkan kawasan permukiman kumuh di wilayah administrasinya, tidak mengikutsertakan tingkat kekumuhan. Tingkat kekumuhan ini sangat diperlukan, agar didapat solusi penanganan yang tepat. Menurut (Peraturan Menteri Pekerjaan Umum dan Perumahan Rakyat Republik Indonesia Nomor 14/PRT/M/2018 Tentang Pencegahan dan Peningkatan Kualitas Terhadap Perumahan Kumuh dan Permukiman Kumuh, 2018) disebutkan bahwa kawasan kumuh berat dan sedang dengan status lahan legal, penanganan dapat dilakukan dengan peremajaan. Kawasan kumuh berat dan sedang dengan status lahan ilegal, penanganan dapat dilakukan dengan permukiman kembali. Kawasan kumuh ringan dengan status lahan legal, penanganan dapat dilakukan dengan pemugaran. Kawasan kumuh ringan dengan status lahan ilegal, penanganan dapat dilakukan dengan permukiman kembali.

Kawasan Pasar Lambaro merupakan satu-satunya kawasan kumuh yang terdapat di Kecamatan Ingin Jaya dengan luas kumuh mencapai 32,14 Ha (Keputusan Bupati Aceh Besar Nomor 358 Tahun 2019 Tentang Penetapan Kawasan Permukiman Kumuh Perkotaan Dalam Wilayah Kabupaten Aceh Besar, 2019). Dalam luasan tersebut, sebelah utara Kawasan Pasar Lambaro terdapat salah satu kawasan perumahan yang telah banyak mengalami penurunan kualitas infrastruktur dengan luas perumahan kumuh mencapai 3,9 Ha. Berdasarkan pengamatan awal, kawasan perumahan tersebut mempunyai ketidakteraturan bangunan, tingkat kepadatan bangunan yang tinggi, kualitas bangunan yang 
rendah, serta sarana dan prasarana yang tidak memenuhi persyaratan teknis. Permasalahan tersebut telah berkontribusi terhadap timbulnya perumahan kumuh di Kawasan Pasar Lambaro. Solusi penanganan sangat diperlukan, agar tidak meluasnya kawasan kumuh dan dapat mempersempit kawasan kumuh yang ada hingga menjadi kawasan tidak kumuh. Tujuan dari penelitian ini adalah mengevaluasi tingkat kekumuhan pada kawasan perumahan Pasar Lambaro, mengidentifikasi skala prioritas penanganan kawasan perumahan kumuh dan menemukan solusi penanganan kawasan perumahan kumuh

\section{Metode Penelitian}

\subsection{Objek dan Lokasi Penelitian}

Objek dalam penelitian ini adalah fisik infrastruktur, legalitas lahan, dan pertimbangan lain. Fisik infrastruktur meliputi bangunan gedung, jalan lingkungan, penyediaan air minum, drainase lingkungan, pengelolaan air limbah, pengelolaan persampahan, dan proteksi kebakaran. Legalitas lahan meliputi kejelasan status penguasaan lahan dan kesesuaian Rencana Tata Ruang (RTR). Pertimbangan lain meliputi nilai strategis lokasi, kependudukan, dan kondisi sosial, ekonomi, serta budaya. Lokasi penelitian dilaksanakan di Kawasan Pasar Lambaro, Kecamatan Ingin Jaya, Kabupaten Aceh Besar. Luas kumuh Kawasan Pasar Lambaro berdasarkan Keputusan Bupati Aceh Besar Nomor 358 Tahun 2019 mencapai 32,14 Ha, sedangkan kawasan perumahan kumuh di Pasar Lambaro yang dievaluasi adalah seluas 3,9 $\mathrm{Ha}$.

\subsection{Pengumpulan Data} berikut:

Pengumpulan data dalam penelitian ini adalah dapat diuraikan sebagai

1. Pengumpulan data observasi

Observasi ini bertujuan untuk memperoleh kondisi fisik infrastruktur pada kawasan perumahan Pasar Lambaro. Fisik infrastruktur yang diobservasi meliputi aspek bangunan gedung, jalan lingkungan, penyediaan air minum, drainase lingkungan, pengelolaan air limbah, pengelolaan persampahan, dan proteksi kebakaran. Alat bantu yang digunakan dalam observasi adalah kamera digital, meteran gulungan, bolpoin, dan formulir.

2. Pengumpulan data wawancara

Wawancara ini bertujuan untuk menilai legalitas lahan dan pertimbangan lain pada kawasan perumahan Pasar Lambaro dari narasumber. Narasumber dalam penelitian ini berjumlah sebanyak 1 orang yaitu aparat desa, dalam hal ini Geuchik Gampong Lambaro. Legalitas lahan yang diwawancara meliputi kejelasan status penguasaan lahan dan kesesuaian RTR. Pertimbangan lain yang diwawancara meliputi nilai strategis lokasi, kependudukan, dan kondisi sosial, ekonomi, serta budaya.

\subsection{Analisis Data}

Analisis data ini menggunakan analisis analisis skoring (pembobotan) dan analisis deskriptif. Hal ini dapat dijelaskan sebagai berikut:

1. Analisis skoring digunakan untuk mengevaluasi tingkat kekumuhan pada kawasan perumahan Pasar Lambaro. Evaluasi tingkat kekumuhan menggunakan Petunjuk Teknis (Juknis) dari (Peraturan Menteri Pekerjaan 
Umum dan Perumahan Rakyat Republik Indonesia Nomor 14/PRT/M/2018 Tentang Pencegahan dan Peningkatan Kualitas Terhadap Perumahan Kumuh dan Permukiman Kumuh, 2018). Langkah-langkah analisis skoring ini dapat diuraikan sebagai berikut:

a. Mengidentifikasi kondisi kekumuhan

Identifikasi kondisi kekumuhan meliputi aspek bangunan gedung, jalan lingkungan, penyediaan air minum, drainase lingkungan, pengelolaan air limbah, pengelolaan persampahan, dan proteksi kebakaran. Setiap aspek kondisi kekumuhan mempunyai kriteria masing-masing. Hasil observasi data numerik selanjutnya dilakukan perhitungan agar dapat menilai parameter dari setiap kriteria. Persentase yang diperoleh dari hasil perhitungan, selanjutnya barulah dapat menilai parameter yang secara bersamaan diperoleh nilai skor. Nilai skor seluruh kriteria pada kondisi kekumuhan selanjutnya ditotalkan. Total nilai skor yang berkisar 19-44 menunjukkan kumuh ringan, total nilai skor 45-70 menunjukkan kumuh sedang, dan total nilai skor yang berkisar 71-95 menunjukkan kumuh berat.

b. Mengidentifikasi legalitas lahan Identifikasi legalitas lahan meliputi kriteria kejelasan status penguasaan lahan dan kesesuaian RTR. Setiap kriteria legalitas lahan mempunyai parameter masing-masing. Hasil wawancara dengan Geuchik Gampong Lambaro selanjutnya dilakukan penilaian parameter dari setiap kriteria, yang secara bersamaan diperoleh nilai skor. Nilai skor negatif (-) menunjukkan status lahan tidak legal dan nilai skor positif (+) menunjukkan status lahan legal.

c. Mengidentifikasi pertimbangan lain

Identifikasi pertimbangan lain meliputi nilai strategis lokasi, kependudukan, dan kondisi sosial, ekonomi, serta budaya. Setiap kriteria pertimbangan lain mempunyai parameter masing-masing. Hasil wawancara dengan Geuchik Gampong Lambaro selanjutnya dilakukan penilaian parameter dari setiap kriteria, yang secara bersamaan diperoleh nilai skor. Nilai skor seluruh kriteria pada pertimbangan lain ditotalkan. Total nilai skor yang berkisar 1-5 menunjukkan pertimbangan lain rendah, total nilai skor 6-10 menunjukkan pertimbangan lain sedang, dan total nilai skor yang berkisar 11-15 menunjukkan pertimbangan lain tinggi.

d. Menentukan skala prioritas penanganan

Skala prioritas penanganan perumahan kumuh mempunyai peringkat 1 sampai 9. Prioritas 1 apabila kumuh berat, status lahan legal, dan pertimbangan lain tinggi. Prioritas 1 apabila kumuh berat, status lahan tidak legal, dan pertimbangan lain tinggi. Prioritas 2 apabila kumuh sedang, status lahan legal, dan pertimbangan lain tinggi. Prioritas 2 apabila kumuh sedang, status lahan tidak legal, dan pertimbangan lain tinggi. Prioritas 3 apabila kumuh ringan, status lahan legal, dan pertimbangan lain tinggi. Prioritas 3 apabila kumuh ringan, status lahan tidak legal, dan pertimbangan lain tinggi. Prioritas 4 apabila kumuh berat, status lahan legal, dan pertimbangan lain sedang. Prioritas 4 apabila kumuh berat, status lahan tidak legal, dan pertimbangan lain sedang. Prioritas 5 apabila kumuh sedang, status lahan legal, dan pertimbangan lain sedang. Prioritas 
5 apabila kumuh sedang, status lahan tidak legal, dan pertimbangan lain sedang. Prioritas 6 apabila kumuh ringan, status lahan legal, dan pertimbangan lain sedang. Prioritas 6 apabila kumuh ringan, status lahan tidak legal, dan pertimbangan lain sedang. Prioritas 7 apabila kumuh berat, status lahan legal, dan pertimbangan lain rendah. Prioritas 7 apabila kumuh berat, status lahan tidak legal, dan pertimbangan lain rendah. Prioritas 8 apabila kumuh sedang, status lahan legal, dan pertimbangan lain rendah. Prioritas 8 apabila kumuh sedang, status lahan tidak legal, dan pertimbangan lain rendah. Prioritas 9 apabila kumuh ringan, status lahan legal, dan pertimbangan lain rendah. Prioritas 9 apabila kumuh ringan, status lahan tidak legal, dan pertimbangan lain rendah.

2. Analisis deskriptif digunakan untuk mendeskripsikan solusi penanganan kawasan perumahan kumuh yang timbul di Pasar Lambaro berdasarkan hasil evaluasi yang telah dinilai. Solusi penanganan kawasan perumahan kumuh menggunakan Juknis dari (Peraturan Menteri Pekerjaan Umum dan Perumahan Rakyat Republik Indonesia Nomor 14/PRT/M/2018 Tentang Pencegahan dan Peningkatan Kualitas Terhadap Perumahan Kumuh dan Permukiman Kumuh, 2018). Solusi penanganan kawasan perumahan kumuh dilakukan berdasarkan penanganan fisik infrastruktur. Penanganan fisik infrastruktur dilakukan untuk bangunan gedung, jalan lingkungan, penyediaan air minum, drainase lingkungan, pengelolaan air limbah, pengelolaan persampahan, dan proteksi kebakaran. Langkah-langkah penanganan fisik infrastruktur ini adalah meninjau kembali hasil evaluasi kondisi kekumuhan dan legalitas lahan dan menetapkan pola penanganan melalui pemugaran, peremajaan, dan permukiman kembali.

\section{Hasil dan Pembahasan}

\subsection{Kondisi Fisik Infrastruktur}

Kawasan perumahan Pasar Lambaro yang ditinjau terletak di Dusun Lhok Pawoh, Kecamatan Ingin Jaya, Kabupaten Aceh Besar, Provinsi Aceh. Delineasi kawasan perumahan Pasar Lambaro di Dusun Lhok Pawoh mempunyai luas 3,9 Ha. Jumlah bangunan pada luas kawasan tersebut terdapat sebanyak 58 unit, dengan jumlah penduduk sebanyak 315 jiwa dari 65 Kepala Keluarga (KK). Berdasarkan hasil observasi, maka kondisi setiap aspek pada kawasan perumahan Pasar Lambaro dapat dilihat pada Tabel 1.

Tabel 1 Kondisi fisik infrastruktur

\begin{tabular}{|c|c|c|c|c|}
\hline No. & Aspek & Observasi & Numerik & Satuan \\
\hline 1 & Kondisi bangunan gedung & & & \\
\hline a & Ketidakteraturan bangunan & Jumlah bangunan tidak teratur & 51 & Unit \\
\hline "b' & $\begin{array}{l}\text { Tingkat } \\
\text { bangunan }\end{array}$ & $\begin{array}{l}\text { Luas kawasan dengan kepadatan > } \\
200 / 250 \text { unit/ha }\end{array}$ & 58 & Unit/Ha \\
\hline $\mathrm{c}$ & $\begin{array}{lr}\text { Ketidaksesuaian } & \text { dengan } \\
\text { persyaratan } & \text { teknis } \\
\text { bangunan } & \end{array}$ & $\begin{array}{l}\text { Jumlah bangunan tidak sesuai } \\
\text { teknis }\end{array}$ & 23 & Unit \\
\hline 2 & Kondisi jalan lingkungan & & & \\
\hline \multirow[t]{2}{*}{ a } & $\begin{array}{l}\text { Cakupan pelayanan jalan } \\
\text { lingkungan }\end{array}$ & $\begin{array}{l}\text { Panjang jalan ideal (standar } \\
\text { minimal) }\end{array}$ & 871 & $\mathrm{~m}$ \\
\hline & & Panjang jalan eksisting & 658 & $\mathrm{~m}$ \\
\hline $\begin{array}{l}\text { Eva } \\
\text { Kal }\end{array}$ & $\begin{array}{l}\text { luasi Kekumuhan Pada Kawas } \\
\text { upaten Aceh Besar - H. Adlan, }\end{array}$ & $\begin{array}{l}\text { Perumahan Pasar Lambaro Kecamat } \\
\text { Yulianur, Izziah }\end{array}$ & Jaya & 205 \\
\hline
\end{tabular}




\begin{tabular}{|c|c|c|c|c|}
\hline b & $\begin{array}{l}\text { Kualitas permukaan jalan } \\
\text { lingkungan }\end{array}$ & $\begin{array}{l}\text { Panjang jalan dengan permukaan } \\
\text { retak dan perubahan bentuk }\end{array}$ & 40 & $\mathrm{~m}$ \\
\hline 3 & Kondisi penyediaan air minu & & & \\
\hline $\mathrm{a}$ & $\begin{array}{l}\text { Ketersediaan akses aman air } \\
\text { minum }\end{array}$ & $\begin{array}{l}\text { Jumlah KK tidak terakses air } \\
\text { minum berkualitas }\end{array}$ & 23 & KK \\
\hline $\mathrm{b}$ & $\begin{array}{l}\text { Tidak terpenuhinya } \\
\text { kebutuhan air minum }\end{array}$ & $\begin{array}{l}\text { Jumlah KK tidak terpenuhi air } \\
\text { minum cukup }\end{array}$ & 23 & KK \\
\hline 4 & Kondisi drainase lingkungan & & & \\
\hline \multirow[t]{2}{*}{$\mathrm{a}$} & $\begin{array}{l}\text { Ketidakmampuan } \\
\text { mengalirkan limpasan air }\end{array}$ & $\begin{array}{l}\text { Luas kawasan yang terkena } \\
\text { genangan }\end{array}$ & 0,003 & $\mathrm{Ha}$ \\
\hline & & $\begin{array}{l}\text { Panjang drainase ideal (standar } \\
\text { minimal) }\end{array}$ & 871 & $\mathrm{~m}$ \\
\hline $\mathrm{b}$ & Ketidaktersediaan drainase & Panjang saluran drainase eksisting & 238 & $\mathrm{~m}$ \\
\hline $\mathrm{c}$ & Kualitas konstruksi drainase & Panjang saluran drainase rusak & 96 & m \\
\hline 5 & Kondisi pengelolaan air limb & & & \\
\hline $\mathrm{a}$ & $\begin{array}{l}\text { Sistem pengelolaan air } \\
\text { limbah tidak sesuai standar } \\
\text { teknis }\end{array}$ & $\begin{array}{l}\text { Jumlah KK tidak terakses sistem } \\
\text { air limbah standar }\end{array}$ & 18 & KK \\
\hline $\mathrm{b}$ & $\begin{array}{llr}\text { Prasarana dan } & \text { sarana } \\
\text { pengelolaan air } & \text { limbah } \\
\text { tidak sesuai } & \text { dengan } \\
\text { persyaratan teknis } & \\
\end{array}$ & $\begin{array}{l}\text { Jumlah KK dengan sarana dan } \\
\text { prasarana air limbah tidak sesuai } \\
\text { standar teknis }\end{array}$ & 18 & KK \\
\hline 6 & Kondisi pengelolaan persamp & bahan & & \\
\hline $\mathrm{a}$ & $\begin{array}{l}\text { Prasarana dan sarana } \\
\text { persampahan tidak sesuai } \\
\text { dengan persyaratan teknis }\end{array}$ & $\begin{array}{l}\text { Jumlah KK dengan sarana } \\
\text { prasarana pengolahan sampah yang } \\
\text { tidak sesuai standar teknis }\end{array}$ & 65 & KK \\
\hline $\mathrm{b}$ & $\begin{array}{l}\text { Sistem pengelolaan } \\
\text { persampahan yang tidak } \\
\text { sesuai standar teknis }\end{array}$ & $\begin{array}{l}\text { Jumlah KK dengan sistem } \\
\text { pengolahan sampah tidak } \\
\text { standar teknis }\end{array}$ & 65 & KK \\
\hline 7 & Kondisi proteksi kebakaran & & & \\
\hline $\mathrm{a}$ & $\begin{array}{l}\text { Ketidaktersediaan prasarana } \\
\text { proteksi kebakaran }\end{array}$ & $\begin{array}{l}\text { Jumlah bangunan tidak terlayani } \\
\text { prasarana proteksi kebakaran }\end{array}$ & 0 & Unit \\
\hline $\mathrm{b}$ & $\begin{array}{l}\text { Ketidaktersediaan sarana } \\
\text { proteksi kebakaran }\end{array}$ & $\begin{array}{l}\text { Jumlah bangunan tidak terlayani } \\
\text { sarana proteksi kebakaran }\end{array}$ & 58 & Unit \\
\hline
\end{tabular}

\subsection{Identifikasi Kondisi Kekumuhan}

Kondisi kekumuhan pada kawasan perumahan Pasar Lambaro diidentifikasi berdasarkan Juknis dari Permen PUPR RI No. 14/PRT/M/2018, melalui hasil observasi. Setiap aspek tersebut mempunyai kriteria dan parameter, dengan nilai skor tersendiri. Dalam hal ini parameter dengan persentase $76 \%-100 \%$ mempunyai nilai skor 5, persentase 51\% - 75\% mempunyai nilai skor 3, persentase $25 \%$ - $50 \%$ mempunyai nilai skor 1 , dan persentase $0 \%-24 \%$ tidak mempunyai nilai skor. Berdasarkan hasil observasi dan analisis skoring, maka penilaian kondisi kekumuhan pada kawasan perumahan Pasar Lambaro dapat dilihat pada Tabel 2 yang memperlihatkan bahwa total nilai skor diperoleh sebesar 25 yang berada pada rentang 19-44, sehingga menunjukkan tingkat kekumuhan pada kawasan perumahan dikategorikan kumuh ringan. Kumuh ringan pada kawasan perumahan Pasar Lambaro disebabkan oleh 5 aspek yaitu aspek kondisi bangunan gedung, penyediaan air minum, pengelolaan air limbah, pengelolaan persampahan, dan proteksi kebakaran. Kekumuhan pada aspek kondisi bangunan 
gedung disebabkan oleh $88 \%$ bangunan pada lokasi tidak memiliki keteraturan dan $40 \%$ bangunan pada lokasi tidak memenuhi persyaratan teknis.

Tabel 2 Penilaian kondisi kekumuhan

\begin{tabular}{|c|c|c|c|c|}
\hline No. & Aspek dan Kriteria & Parameter & $\begin{array}{c}\text { Hasil } \\
\text { Hitung }\end{array}$ & $\begin{array}{l}\text { Nilai } \\
\text { Skor }\end{array}$ \\
\hline 1 & Kondisi bangunan gedung & & & \\
\hline $\mathrm{a}$ & Ketidakteraturan bangunan & $\begin{array}{l}76 \%-100 \% \text { bangunan pada lokasi } \\
\text { tidak memiliki keteraturan }\end{array}$ & $88 \%$ & 5 \\
\hline $\mathrm{b}$ & $\begin{array}{l}\text { Tingkat kepadatan bangunan } \\
\text { yang tinggi yang tidak sesuai } \\
\text { dengan ketentuan rencana } \\
\text { tata ruang }\end{array}$ & - & $7 \%$ & 0 \\
\hline c & $\begin{array}{l}\text { Kualitas bangunan yang tidak } \\
\text { memenuhi syarat }\end{array}$ & $\begin{array}{l}25 \%-50 \% \text { bangunan pada lokasi tidak } \\
\text { memenuhi persyaratan teknis }\end{array}$ & $40 \%$ & 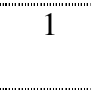 \\
\hline 2 & Kondisi jalan lingkungan & & & \\
\hline $\mathrm{a}$ & $\begin{array}{l}\text { Jaringan jalan lingkungan } \\
\text { tidak melayani seluruh } \\
\text { lingkungan perumahan atau } \\
\text { permukiman }\end{array}$ & - & $24 \%$ & 0 \\
\hline $\mathrm{b}$ & $\begin{array}{l}\text { Kualitas permukaan jalan } \\
\text { lingkungan buruk }\end{array}$ & - & $6 \%$ & " \\
\hline 3 & Kondisi penyediaan air minum & & & \\
\hline $\mathrm{a}$ & $\begin{array}{l}\text { Akses aman air minum tidak } \\
\text { tersedia }\end{array}$ & $\begin{array}{l}25 \%-50 \% \text { populasi tidak dapat } \\
\text { mengakses air minum yang aman }\end{array}$ & $35 \%$ & 1 \\
\hline $\mathrm{b}$ & $\begin{array}{l}\text { Kebutuhan air minum } \\
\text { minimal setiap individu tidak } \\
\text { terpenuhi }\end{array}$ & $\begin{array}{l}25 \%-50 \% \text { populasi tidak terpenuhi } \\
\text { kebutuhan air minum minimalnya }\end{array}$ & $35 \%$ & 1 \\
\hline 4 & Kondisi drainase lingkungan & & & \\
\hline $\mathrm{a}$ & $\begin{array}{l}\text { Drainase lingkungan tidak } \\
\text { tersedia }\end{array}$ & - & $6 \%$ & 0 \\
\hline $\mathrm{b}$ & $\begin{array}{l}\text { Drainase lingkungan tidak } \\
\text { mampu mengalirkan limpasan } \\
\text { air hujan sehingga } \\
\text { menimbulkan genangan }\end{array}$ & - & $0 \%$ & 0 \\
\hline $\mathrm{c}$ & $\begin{array}{l}\text { Kualitas konstruksi drainase } \\
\text { lingkungan buruk }\end{array}$ & - & $0 \%$ & 0 \\
\hline 5 & Kondisi pengelolaan air limbah & & & \\
\hline$a$ & $\begin{array}{l}\text { Sistem pengelolaan air limbah } \\
\text { tidak memenuhi persyaratan } \\
\text { teknis }\end{array}$ & $\begin{array}{l}25 \%-50 \% \text { area memiliki sistem air } \\
\text { limbah yang tidak sesuai standar teknis }\end{array}$ & $28 \%$ & 1 \\
\hline b & $\begin{array}{l}\text { Prasarana dan sarana } \\
\text { pengelolaan air limbah tidak } \\
\text { memenuhi persyaratan teknis }\end{array}$ & $\begin{array}{l}25 \%-50 \% \text { area memiliki prasarana air } \\
\text { limbah tidak sesuai persyaratan teknis }\end{array}$ & $28 \%$ & "1 1 \\
\hline 6 & Kondisi pengelolaan persampah & & & \\
\hline $\mathrm{a}$ & $\begin{array}{l}\text { Prasarana dan sarana } \\
\text { persampahan tidak memenuhi } \\
\text { persyaratan teknis }\end{array}$ & $\begin{array}{l}76 \%-100 \% \text { area memiliki prasarana } \\
\text { pengelolaan persampahan yang tidak } \\
\text { memenuhi persyaratan teknis }\end{array}$ & $100 \%$ & 5 \\
\hline b & $\begin{array}{l}\text { Sistem pengelolaan } \\
\text { persampahan tidak memenuhi } \\
\text { persyaratan teknis }\end{array}$ & $\begin{array}{l}76 \%-100 \% \text { area memiliki sistem } \\
\text { persampahan tidak sesuai standar }\end{array}$ & $100 \%$ & 5 \\
\hline 7 & Kondisi proteksi kebakaran & & & \\
\hline \multicolumn{4}{|c|}{$\begin{array}{l}\text { Evaluasi Kekumuhan Pada Kawasan Perumahan Pasar Lambaro Kecamatan Ingin Jaya } \\
\text { Kabupaten Aceh Besar - H. Adlan, A. Yulianur, Izziah }\end{array}$} & 207 \\
\hline
\end{tabular}




\begin{tabular}{|c|c|c|c|c|}
\hline a & $\begin{array}{l}\text { Prasarana proteksi kebakaran } \\
\text { tidak tersedia }\end{array}$ & - & $0 \%$ & 0 \\
\hline \multirow[t]{2}{*}{ b } & $\begin{array}{l}\text { Sarana proteksi kebakaran } \\
\text { tidak tersedia }\end{array}$ & $\begin{array}{l}76 \%-100 \% \text { area tidak memiliki sarana } \\
\text { proteksi kebakaran }\end{array}$ & $100 \%$ & 5 \\
\hline & & Total nil & ii skor & 25 \\
\hline
\end{tabular}

Kekumuhan pada aspek kondisi penyediaan air minum disebabkan oleh $35 \%$ populasi tidak dapat mengakses air minum yang aman dan $35 \%$ populasi tidak terpenuhi kebutuhan air minum minimal. Kekumuhan pada aspek kondisi pengelolaan air limbah disebabkan oleh $28 \%$ area memiliki sistem air limbah yang tidak sesuai standar teknis dan $28 \%$ area memiliki prasarana air limbah tidak sesuai persyaratan teknis. Kekumuhan pada aspek kondisi pengelolaan persampahan disebabkan oleh $100 \%$ area memiliki prasarana pengelolaan persampahan yang tidak memenuhi persyaratan teknis dan $100 \%$ area memiliki sistem persampahan tidak sesuai standar. Kekumuhan pada aspek kondisi proteksi kebakaran disebabkan oleh $100 \%$ area tidak memiliki sarana proteksi kebakaran.

Hasil penelitian ini mempunyai perbedaan dengan beberapa penelitian terdahulu. Kekumuhan pada pemukiman di kelurahan Calaca, Kota Manado disebabkan oleh faktor jarak antara bangunan satu dengan yang lain, tingginya tingkat kepadatan penduduk, rendahnya tingkat pendapatan, rendahnya tingkat pendidikan masyarakat, banyaknya penduduk yang bermata pencaharian informal, keterbatasan lahan, dan rendahnya tingkat kepedulian maupun kesadaran masyarakat terhadap lingkungan serta kurangnya partisipasi masyarakat terhadap penataan pemukiman kumuh (Lantang et al., 2013). Kekumuhan pada kelurahan Beringin, Kelurahan Sungai Asam, Kelurahan Orang Kayo Hitam, dan Kelurahan Pasar Jambi disebabkan oleh masalah pelayanan persampahan, genangan drainase, pelayanan air minum, jumlah bangunan temporer, jarak antar bangunan yang rapat, dan dominasi status tanah atau kepemilikan tanah (Istikasari and Khadiyanto, 2014). Tingkat kerawanan kebakaran pada permukiman kumuh di Kelurahan Lingkas Ujung, Kota Tarakan dipengaruhi oleh kepadatan bangunan, aksesibilitas, struktur bangunan dan sumber air (Oktaviansyah, 2012).

\subsection{Identifikasi Legalitas Lahan}

Legalitas lahan pada kawasan perumahan diidentifikasi berdasarkan Juknis dari Permen PUPR RI No. 14/PRT/M/2018, melalui wawancara dengan Geuchik Gampong Lambaro. Legalitas lahan yang diidentifikasi terdapat 2 kriteria yaitu kejelasan status penguasaan lahan dan kesesuaian Rencana Tata Ruang (RTR). Setiap kriteria mempunyai parameter dengan nilai skor tersendiri. Dalam hal ini parameter dengan kondisi yang baik mempunyai nilai skor positif (+) dan kondisi yang tidak baik mempunyai nilai skor negatif (-). Berdasarkan hasil wawancara, maka penilaian legalitas lahan dapat dilihat pada Tabel 3.

Tabel 3 Penilaian legalitas lahan

\begin{tabular}{cclcc}
\hline No. & \multicolumn{1}{c}{ Kriteria } & \multicolumn{1}{c}{ Parameter } & Nilai \\
\hline 1 & $\begin{array}{l}\text { Kejelasan status } \\
\text { penguasaan lahan }\end{array}$ & $\begin{array}{l}\text { Sebagian lokasi tidak memiliki kejelasan status } \\
\text { penguasaan lahan, baik milik sendiri atau milik pihak } \\
\text { lain }\end{array}$ & $(-)$ \\
\hline 2 & Kesesuaian RTR & $\begin{array}{l}\text { Sebagian lokasi berada bukan pada zona peruntukan } \\
\text { perumahan/permukiman sesuai RTR }\end{array}$ & $(-)$ \\
\hline
\end{tabular}

Evaluasi Kekumuhan Pada Kawasan Perumahan Pasar Lambaro Kecamatan Ingin Jaya 208 Kabupaten Aceh Besar - H. Adlan, A. Yulianur, Izziah 
Tabel 3 memperlihatkan bahwa untuk kriteria kejelasan status penguasaan lahan pada kawasan perumahan Pasar Lambaro mempunyai nilai skor negatif (-). Hal ini berarti bahwa kawasan perumahan Pasar Lambaro sebagiannya belum mempunyai kejelasan status penguasaan lahan. Jumlah rumah dalam luasan delineasi dari hasil observasi adalah sebanyak 58 unit. Dalam hal ini dari 58 unit, sebagian besarnya mempunyai lahan legal sebanyak 55 unit dan sebagian kecilnya mempunyai lahan ilegal sebanyak 3 unit. Tabel 3 juga memperlihatkan bahwa untuk kriteria kesesuaian RTR pada kawasan perumahan Pasar Lambaro mempunyai nilai skor negatif (-). Hal ini berarti bahwa kawasan perumahan Pasar Lambaro sebagiannya belum mempunyai kesesuaian RTR. Keseuaian RTR dapat diketahui dari lokasi rumah berada pada zona perumahan. Dalam hal ini dari 58 unit, sebagian besarnya dibangun pada zona perumahan sebanyak 55 unit dan sebagian kecilnya dibangun pada zona sempadan sungai sebanyak 3 unit.

\subsection{Identifikasi Pertimbangan Lain}

Pertimbangan lain pada kawasan perumahan Pasar Lambaro diidentifikasi berdasarkan Juknis dari Permen PUPR RI No. 14/PRT/M/2018, melalui wawancara dengan Geuchik Gampong Lambaro. Pertimbangan lain yang diidentifikasi terdapat 3 kriteria yaitu nilai strategis lokasi, kependudukan, dan kondisi sosial, ekonomi, dan budaya. Setiap kriteria mempunyai parameter dengan nilai skor tersendiri. Dalam hal ini parameter dengan kondisi yang baik mempunyai nilai skor 5, kondisi yang kurang baik mempunyai nilai skor 3, dan kondisi yang tidak baik mempunyai nilai skor 1. Berdasarkan hasil wawancara, maka penilaian pertimbangan lain pada kawasan perumahan Pasar Lambaro dapat lihat pada Tabel 4.

Tabel 4 Penilaian pertimbangan lain

\begin{tabular}{cllc}
\hline No. & Kriteria & \multicolumn{1}{c}{ Parameter } & Nilai \\
\hline 1 & $\begin{array}{l}\text { Nilai strategis } \\
\text { lokasi }\end{array}$ & Lokasi terletak pada fungsi strategis kabupaten/kota & 5 \\
2 & Kependudukan & Kepadatan penduduk pada lokasi sebesar $>200$ jiwa/ha & 5 \\
\hline 3 & $\begin{array}{l}\text { Kondisi sosial, } \\
\text { ekonomi, dan } \\
\text { budaya }\end{array}$ & $\begin{array}{l}\text { Lokasi memiliki potensi sosial, ekonomi, dan budaya } \\
\text { untuk dikembangkan atau dipelihara }\end{array}$ & 5 \\
\hline & & Total nilai skor & 15 \\
\hline
\end{tabular}

Tabel 4 memperlihatkan bahwa total nilai skor diperoleh sebesar 15 yang berada pada rentang $11-15$, sehingga kawasan perumahan Pasar Lambaro dikategorikan pertimbangan lain tinggi.

\subsection{Skala Prioritas Penanganan Kawasan Perumahan Kumuh}

Skala prioritas adalah proses pertimbangan beberapa bagian dalam menentukan sebuah keputusan. Beberapa bagian yang perlu dipertimbangkan dalam menentukan prioritas penanganan kawasan perumahan kumuh di Pasar Lambaro adalah kondisi kekumuhan, legalitas lahan, dan pertimbangan lain. Ketiga bagian tersebut telah dievaluasi berdasarkan Juknis dari Permen PUPR RI No. 14/PRT/M/2018 melalui hasil observasi dan wawancara Geuchik Gampong Lambaro dengan menggunakan analisis skoring (pembobotan). Hasil evaluasi 
kondisi kekumuhan pada kawasan perumahan Pasar Lambaro adalah termasuk dalam klasifikasi kumuh ringan dengan total nilai skor sebesar 25. Hasil evaluasi legalitas lahan pada kawasan perumahan Pasar Lambaro adalah termasuk dalam klasifikasi status lahan tidak legal dengan nilai skor negatif (-). Hasil evaluasi pertimbangan lain pada kawasan perumahan Pasar Lambaro adalah termasuk dalam klasifikasi pertimbangan lain tinggi dengan total nilai skor sebesar 15 . Berdasarkan Juknis bila kondisi kekumuhan termasuk dalam kumuh ringan, legalitas lahan termasuk dalam status lahan tidak legal, dan pertimbangan lain termasuk dalam pertimbangan lain tinggi, maka kawasan kumuh tersebut tergolong dalam klasifikasi C2. Klasifikasi C2 adalah skala prioritas penanganan kawasan perumahan kumuh ke 3. Oleh karena itu, kawasan perumahan kumuh di Pasar Lambaro masuk dalam skala prioritas penanganan ke 3. Dengan demikian, Pemerintah Kabupaten Aceh Besar untuk mengurangi luas kawasan permukiman kumuh di wilayah administrasinya dengan keterbatasan anggaran yang ada, maka perlu menangani terlebih dahulu kawasan yang menjadi prioritas 1 dan 2. Dalam hal ini kawasan yang menjadi prioritas 1 dan 2, tidak dievaluasi dalam penelitian ini. Untuk mengetahui kawasan yang menjadi prioritas 1 dan 2, maka peneliti selanjutnya dapat mengevaluasi kawasan permukiman kumuh yang terdapat di dalam Surat Keputusan Bupati Aceh Besar Nomor 358 Tahun 2019. Adapun kawasan kumuh lainnya yang tertera pada surat tersebut adalah Kawasan Lhok Seunong, Lampeunurut Ujong Blang, Garut, Baet, Cadek, Lambaroe Bileu, dan Kawasan Barona.

Penanganan permukiman kumuh di Desa Bale Atu dan seluruh dusunnya berdasarkan tipologi dan fisik infrastruktur, masuk dalam klasifikasi C1. Klasifikasi $\mathrm{C} 1$ merupakan kawasan yang mempunyai skala prioritas penanganan ke 3. Oleh karena itu Desa Bale Atu dan seluruh dusunnya merupakan kawasan yang masuk dalam skala prioritas penanganan ke 3 di Kecamatan Lut Tawar. Sementara skala prioritas penanganan ke 1, 2, 4, 5, 6, 7, 8 dan 9 terdapat pada desa lain disetiap kecamatan yang ada di Kabupaten Aceh tengah, yang tidak dievaluasi dalam penelitian (Julianda et al., 2018).

\subsection{Solusi Penanganan Kawasan Perumahan Kumuh}

Kawasan perumahan Pasar Lambaro tergolong dalam klasifikasi kumuh ringan dengan status lahan legal dan ilegal. Berdasarkan Permen PUPR RI No. 14/PRT/M/2018, kawasan yang memiliki klasifikasi kumuh ringan dengan status lahan legal maka pola penanganan yang dilakukan adalah pemugaran. Sementara, kawasan yang memiliki klasifikasi kumuh ringan dengan status lahan ilegal, maka pola penanganan yang dilakukan adalah pemukiman kembali. Oleh karena itu, solusi penanganan kawasan perumahan kumuh di Pasar Lambaro dilakukan melalui pemugaran untuk lahan legal dan pemukiman kembali untuk lahan ilegal.

Pemugaran adalah kegiatan yang dilakukan untuk memperbaiki kembali kawasan perumahan sehingga menjadi layak huni. Dalam hal ini, pemugaran perlu dilakukan untuk 55 unit rumah yang berada di zona perumahan dan mempunyai kejelasan status penguasaan lahan. Solusi penanganan melalui pemugaran hanya dilakukan pada aspek-aspek fisik infrastruktur yang menyebabkan kekumuhan yaitu bangunan gedung, penyediaan air minum, pengelolaan air limbah, pengelolaan persampahan, dan proteksi kebakaran. Adapun bentuk solusi 
penanganan kawasan perumahan kumuh di Pasar Lambaro melalui pemugaran adalah sebagai berikut:

1. Penanganan pada aspek bangunan gedung adalah merehabilitasi bangunan gedung agar fungsi dan massa bangunan kembali sesuai dengan kondisi saat awal dibangun.

2. Penanganan pada aspek penyediaan air minum adalah merehabilitasi unit penyediaan air minum untuk mengembalikan kondisi sesuai dengan persyaratan teknis saat awal dibangun/disediakan, seperti penggantian komponen pada unit-unit air baku, unit produksi, jaringan unit distribusi, dan unit pelayanan.

3. Penanganan pada aspek pengelolaan air limbah adalah merehabilitasi unit pengelolaan air limbah untuk mengembalikan kondisi sesuai dengan persyaratan teknis saat awal dibangun/disediakan, seperti penggantian komponen pada Sistem Pengelolaan Air Limbah Terpusat (SPAL-T) seperti komponen pemipaan, penggantian komponen pada Sistem Pengelolaan Air Limbah Setempat (SPAL-S) seperti tangki septik, cubluk, biofiter, dan komponen sejenis.

4. Penanganan pada aspek pengelolaan persampahan adalah merehabilitasi unit pengelolaan persampahan untuk mengembalikan kondisi sesuai dengan persyaratan teknis saat awal dibangun, seperti penggantian sarana dan prasarana pemilahan, pengumpulan, pengangkutan, dan pengolahan.

5. Penanganan pada aspek proteksi kebakaran adalah merehabilitasi unit proteksi kebakaran untuk mengembalikan kondisi sesuai dengan persyaratan teknis saat awal dibangun, seperti penggantian sarana dan prasarana proteksi kebakaran.

Pemukiman kembali adalah kegiatan memindahkan masyarakat terdampak dari kawasan perumahan kumuh yang tidak mungkin dibangun kembali ke kawasan lainnya, karena tidak sesuai dengan rencana tata ruang atau rawan terhadap bencana. Dalam hal ini, pemukiman kembali perlu dilakukan untuk 3 unit rumah yang berada di zona sempadan sungai dan tidak mempunyai kejelasan status penguasaan lahan. Solusi penanganan hanya dilakukan pada aspek-aspek fisik infrastruktur yang menyebabkan kekumuhan yaitu bangunan gedung, penyediaan air minum, pengelolaan air limbah, pengelolaan persampahan, dan proteksi kebakaran. Adapun bentuk solusi penanganan kawasan perumahan kumuh di Pasar Lambaro melalui pemukiman kembali adalah sebagai berikut:

1. Penanganan pada aspek bangunan gedung adalah melakukan pembangunan pada kawasan baru yang sesuai arahan rencana tata ruang dan sesuai dengan daya tampungnya.

2. Penanganan pada aspek penyediaan air minum adalah menyediakan air minum pada kawasan baru yang sesuai arahan rencana tata ruang dan rencana induk sektor air minum.

3. Penanganan pada aspek pengelolaan air limbah adalah membangun unit pengelolaan air limbah pada kawasan baru yang sesuai arahan rencana tata ruang dan rencana induk sektor pengelolaan air limbah.

4. Penanganan pada aspek pengelolaan persampahan adalah membangun unit pengelolaan persampahan pada kawasan baru yang sesuai arahan rencana tata ruang dan rencana induk sektor pengelolaan persampahan. 
5. Penanganan pada aspek proteksi kebakaran adalah membangun unit proteksi kebakaran pada kawasan baru yang sesuai arahan rencana tata ruang dan rencana induk sektor proteksi kebakaran.

Hasil penelitian ini terdapat perbedaan dengan beberapa penelitian terdahulu. Strategi perencanaan infrastruktur menuju kota tanpa kumuh di Gerung Selatan Kabupaten Lombok Barat adalah untuk tahun pertama (2017) mengentaskan kawasan kumuh secara selaras dengan program (100-0-100) dari Pemerintah Pusat. Strategi untuk tahun kedua (2018) menarik perhatian stakeholder untuk segera menghilangkan predikat kawasan kumuh. Strategi untuk tahun ketiga (2019) meningkatkan antusias masyarakat untuk memberantas kekumuhan dalam mengurangi angka kemiskinan (Kurniawan et al., 2018). Penanganan permukiman kumuh pada Kelurahan Makassar Timur perlu pembongkaran total bangunannya agar dapat dilakukan penataan kembali. Penanganan untuk sirkulasi dalam kawasan permukiman adalah menentukan jalur primer, sekunder, dan lokal pada lokasi perencanaan, mengarahkan sistem sirkulasi pedestrian disamping jalur utama yang mengelilingi kawasan permukiman, dan memberi batas yang jelas dengan cara peninggian pedestrian + 15-20 cm. Penanganan utilitas kawasan dilakukan dengan cara seluruh limbah rumah tangga dalam kawasan dialirkan ke bak kontrol yang cukup besar dan dapat menampung seluruh air limbah dari permukiman (Harisun et al., 2019). Penanganan kawasan permukiman kumuh di Nagari Painan Selatan, Kecamatan IV Jurai dilakukan melelalui permukiman kembali dan peremajaan. Bentuk permukiman kembali pada status tanah illegal dengan skema pembangunan rumah susun sewa oleh pemerintah, dan bentuk penanganan peremajaan pada status tanah legal melalui program perbaikan kampung (Edsadova et al., 2017). Bentuk penanganan permukiman kumuh di Desa Bale Atu berdasarkan tipologi dilakukan melalui penanganan tipologi perbukitan dan berdasarkan fisik infrastruktur dilakukan melalui pola pemugaran (Julianda et al., 2018). Pendekatan penanganan kawasan permukiman kumuh di Kelurahan Pasar Baru dilakukan dengan property development, sedangkan di Kelurahan Balai-balai dilakukan dengan community based development (Rahman et al., 2015).

\section{Kesimpulan dan Saran}

\subsection{Kesimpulan}

Tingkat kekumuhan pada kawasan perumahan Pasar Lambaro termasuk dalam klasifikasi kumuh ringan dengan total nilai skor sebesar 25. Skala prioritas penanganan kawasan perumahan kumuh masuk dalam skala prioritas penanganan ke 3. Solusi penanganan kawasan perumahan kumuh di Pasar Lambaro dilakukan melalui pemugaran untuk lahan legal dan pemukiman kembali untuk lahan ilegal yang difokuskan pada aspek bangunan gedung, penyediaan air minum, pengelolaan air limbah, pengelolaan persampahan, dan proteksi kebakaran.

\subsection{Saran}

Disarankan kepada Pemerintah Kabupaten Aceh Besar, penanganan kawasan perumahan kumuh di Pasar Lambaro dapat dilakukan melalui pemugaran pada lahan legal dan pemukiman kembali pada lahan ilegal, agar kawasan kumuh yang ada dapat dipersempit, hingga menjadi tidak kumuh. Disarankan kepada 
peneliti selanjutnya untuk mengevaluasi tingkat kekumuhan di kawasan lainnya yang ada dalam Surat Keputusan Bupati Aceh Besar Nomor 358 Tahun 2019, agar dapat diketahui tingkat kekumuhan, skala prioritas penanganan, dan solusi penanganan yang tepat.

\section{Daftar Kepustakaan}

Edsadova, D., Haryani, Aditia, E., 2017. Strategi Penanganan Kawasan Permukiman Kumuh di Nagari Painan Selatan Kecamatan IV Jurai.

Harisun, E., Conoras, M.A.M., Darwis, M., 2019. Identifikasi dan Penanganan Kawasan Kumuh pada Kelurahan Makassar Timur. Techno 08, 259-270.

Istikasari, M., Khadiyanto, P., 2014. Identifikasi Permukiman Kumuh di Pusat Kota Jambi. Ruang 2, 301-310.

Julianda, A., Azmeri, Fatimah, E., 2018. Tingkat Kekumuhan Dan Penanganan Pada Permukiman Desa Bale Atu Kecamatan Lut Tawar Kabupaten Aceh Tengah. Arsip Rekayasa Sipil dan Perenc. 1, 1-10.

Keputusan Bupati Aceh Besar Nomor 358 Tahun 2019 Tentang Penetapan Kawasan Permukiman Kumuh Perkotaan Dalam Wilayah Kabupaten Aceh Besar, 2019.

Kurniawan, N., Murtiadi, S., Agustawijaya, D.S., 2018. Strategi Perencanaan Infrastruktur Menuju Kota Tanpa Kumuh (Studi Kasus: Program Kotaku 2019 Gerung Selatan Kabupaten Lombok Barat). Spektrum Sipil 5, 45-47.

Lantang, M., Mononimbar, W., Sangkertadi, Suryono, 2013. Analisis Faktor Kekumuhan Permukiman di Kelurahan Calaca Kota Manado. Sabua 5, 2834.

Oktaviansyah, E., 2012. Penataan Permukiman Kumuh Rawan Bencana Kebakaran di Kelurahan Lingkas Ujung Kota Tarakan. Tata Kota dan Drh. 4, 159-168.

Peraturan Menteri Pekerjaan Umum dan Perumahan Rakyat Republik Indonesia Nomor 14/PRT/M/2018 Tentang Pencegahan dan Peningkatan Kualitas Terhadap Perumahan Kumuh dan Permukiman Kumuh, 2018.

Rahman, F., Nur, H., Tou, H.J., 2015. Identifikasi dan Penanganan Kawasan Permukiman Kumuh Melalui Upaya Peremajaan (Studi Kasus Kelurahan Pasar Baru dan Kelurahan Balai-balai Kota Padang Panjang). 